\section{$48=$}

NASA Technical Memorandum 105982

\section{$1 N-20$ \\ 137554}

\title{
Development of NASA/DOE NTP System Performance Models
}

James T. Walton

Lewis Research Center

Cleveland, Ohio

Prepared for the

10th Space Nuclear Power Symposium sponsored by the University of New Mexico Institute for Space Nuclear Power

Albuquerque, New Mexico, January 10-14, 1993 
$=$

$=$ 


\title{
DEVELOPMENT OF NASA/DOE NTP SYSTEM PERFORMANCE MODELS
}

\author{
James T. Walton \\ Nuclear Propulsion Office \\ NASA Lewis Research Center \\ Cleveland, OH 44135
}

(216) $977-7047$

\begin{abstract}
A critical enabling technology in the evolutionary development of Nuclear Thermal Propulsion (NTP) is the ability to predict the system performance under a variety of operating conditions. The ability to predict the system performance is critical for mission analysis and for control subsystem testing, as well as for the modeling of various failure modes. Performance must be accurately predicted during steady-state and transient operation, such as start-up, shut-down and after-cooling. The development and application of verified and validated system models has the potential to reduce testing, cost and time required for the technology to again reach flight-ready status. An integrated NASA/DOE team was formed in late 1991 to develop and implement a strategy for modeling NTP systems. It is the intent of the interagency team to develop several levels of computer programs, which vary in detail, to simulate NTP systems based on either prismatic, particle or advanced fuel forms. This paper presents an overview of the models under development by the interagency team. In addition, the status of the development and validation efforts for the Level 1 steady-state parametric model will be discussed.
\end{abstract}

\section{INTRODUCTION}

During the summer of 1989, President Bush presented a national vision focused on returning man to the Moon and then travelling on to Mars. This was the commencement of NASA's 
Space Exploration Initiative (SEI). Since that time, a variety of studies and commissions have reasserted the desirability of a Nuclear Thermal Propulsion (NTP) system for interplanetary propulsion to fulfill the Space Exploration Initiative. In addition to reducing the gross launch mass by up to 50 percent and decreasing launch costs systems, nuclear thermal propulsion offers enhanced astronaut safety by lowering the inter-galactic cosmic radiation dose to the crew through reduced mission transit time.

Nuclear thermal propulsion systems operate by using propellant to cool a nuclear reactor core, yielding a high-temperature gas for expansion through a nozzle. The reactor core replaces the combustion process of bipropellant chemical propulsion systems as the source of heat. Because only a single propellant, such as hydrogen with its low molecular weight, is required for NTP, the system can achieve more than twice the thrust efficiency of chemical propulsion.

Because the NTP system integrates a nuclear reactor with chemical rocket technology, NASA and DOE have been working cooperatively on its concept definition and technology development. The concept definition and systems engineering activities involve the development of an NTP configuration which meets astronaut safety, SEI mission requirements, and NTP stage requirements. The primary variable in the system configuration is the nuclear reactor fuel form for which; candidate forms include prismatic, particle, and wire. The technology development activities involve the investigation of (1) high-temperature, long-life (hours) fuels, (2) low mass, high-performance nozzles, (3) high-efficiency, low mass turbopumps, and (4) reliable, autonomous controls and health management systems. 
A critical task in these activities is developing the ability to predict system performance under a variety of operating conditions. The capacity to model system performance is required for concept definition activities to evaluate each configuration on a common basis. This capability also aids the technology development activities by providing a means to evaluate the benefits to the system from component improvements and by providing a diagnostic tool for understanding experiments. Moreover, the ability to predict the system performance is critical for mission analysis, control system testing, and for the modeling of various failure modes. Performance must be accurately predicted during steady-state and transient operation, including startup, shutdown and post operation cooling. System models will access component models for the reactor, nozzle, turbopumps, and lines, along with a propellant properties model. The development and application of verified and validated system models has the potential to reduce the testing, cost and time required for new advanced NTP systems to regain flight-ready status.

An integrated NASA/DOE team was formed in late 1991 to develop and implement a strategy for modeling NTP systems that conform to the schedule for concept definition and technology development activities. An interagency team was formed to integrate the best capabilities available and to assure appropriate peer review. The team members include personnel from the following DOE laboratories: Argonne National Laboratory (ANL), Brookhaven National Laboratory (BNL), Idaho National Engineering Laboratory (INEL), Los Alamos National Laboratory (LANL), Oak Ridge National Laboratory (ORNL), and Sandia National Laboratories (SNL); and personnel from the NASA Lewis Research Center (LeRC) and the Marshall Space Flight Center (MSFC). The team also includes personnel from the DOD Phillips Laboratory to facilitate the interchange of technology developed under the NASA SEI NTP program and the 
DOD Space Nuclear Thermal Propulsion (SNTP) program.

It is the intent of the interagency team to develop several levels of computer programs to simulate NTP system performance based on various fuel forms. The first level will provide rapid, parameterized calculations of overall system performance. Succeeding computer programs will provide analysis of each component in sufficient detail to guide the design teams and experimental efforts. Note, these system models are not intended to replace requisite individual component analysis of the reactor, turbopump or nozzle. The following sections outline the vision and the near-term strategies developed by the interagency NTP system modeling team.

\section{INTERAGENCY TEAM MISSION}

The purpose of the interagency modeling team is to integrate state-of-the-art computational resources and techniques, with the current knowledge base, to produce simulations of NTP system performance. The end products will provide users with a variety of validated and/or verified system models to assist in designing and to reduce the testing, cost, and time to reach a flight ready status. This vision can be best achieved by a NASA/DOE team which can use the unique capabilities of each team member and assure joint support for the resulting models.

\section{TEAM OBJECTIVE}

To realize the vision and meet the users' needs, the objective of the interagency team will be to develop five distinct computer programs, each varying in the level of detail and capability, 
to simulate NTP system performance.

\section{Level 1 Model}

The Level 1 model is envisioned to be a relatively simple parametric system model. The primary focus of this program will be to analyze the performance of a variety of configurations, including NERVA-derivative, particle-bed, and CERMET reactor-based NTP systems. This program is expected to analyze steady-state performance and to require a run time on the order of minutes. The secondary focus of this program will be system design. The target user market for this program includes mission analysis groups, component modeling groups, and concept evaluation teams.

\section{Level 2 Model}

The Level 2 model is envisioned to be a near-term, detailed, transient system analysis program. It may use an existing base architecture program and will be capable of modeling system startup and shutdown as well as system feedbacks and oscillations. Since this level of analysis will involve multidimensional reactor neutronic solutions, this program will be used once reactor designs are reasonably fixed. The program should be capable of handling control drum rotations, turbopump assembly (TPA) startup, stress analysis, decay heating, and detailed nozzle heat transfer analysis accounting for neutron/gamma heating. It is anticipated that this program will not have neutronic criticality and power density analysis integrated into the base architecture although reactor dynamics will be included. The target user market for this 
program includes component modeling groups and concept evaluation teams. The Level 2 model will also be used parametrically by the interagency team to identify modeling requirements for the Level 3 model.

\section{Level 3 Model}

The Level 3 model is envisioned to be a far-term, detailed, transient system analysis program. This integrated performance analysis program will be based on state-of-the-art methodology at the time of the base architecture program development. The component models must be verified by older component models and/or validated by component experimental data. This program will provide information similar to that of the Level 2 model. It is anticipated that this program will have neutronic criticality and power density analysis integrated into the base architecture or will provide a means for easy information transfer through coupling. The target user market for this program includes component modeling groups and concept evaluation teams. This model will include two-phase and multi-dimensional flow capability. The model will also include shock-capturing numerics to allow simulation of severe accident conditions.

\section{Level 4 Model}

The Level 4 model is envisioned to be a modified version of the Level 3 program tuned to model the experimental or flight engine. The target user market for this program includes component modeling groups, control system developers, and engine performance analysts. The Level 4 model is a 1990's version of the Nuclear Engine Transient Analysis Program, NETAP, 
of the NERVA project from the view point that this program was tailored for a specific configuration.

\section{Level 5 Model}

The Level 5 model is envisioned to be a real-time, transient simulation model of the experimental or flight engine. The target user market for this program includes engine operator training groups and flight engine performance review teams. This model is similar to the Common Analog Model, CAM, of the NERVA project. The CAM was developed to describe the dynamic behavior of the NERVA $400 \mathrm{E}$ engine configuration by using correlations and curvefits of actual component physics.

\section{RESULTS AND DISCUSSION}

The strategy and time table for achieving each of the teams' objectives is well presented in the reference by Walton, et. al, 1992. To date, the majority of work has focused on the Level 1 model. The development of the model is guided by the software design requirements document, which was the first task of the team. Based on the requirements, the structure shown in Figure 1 was selected for the Level 1 model. The computational engine is a general finite element fluid system analysis program capable of integrated heat transfer, fluid mechanics and reactor dynamics calculations. Because it is general in nature, the configuration specific information is contained in an extensive input file. To manage input file generation, an interactive input preprocessor will be utilized. A discussion of the data bases and component 


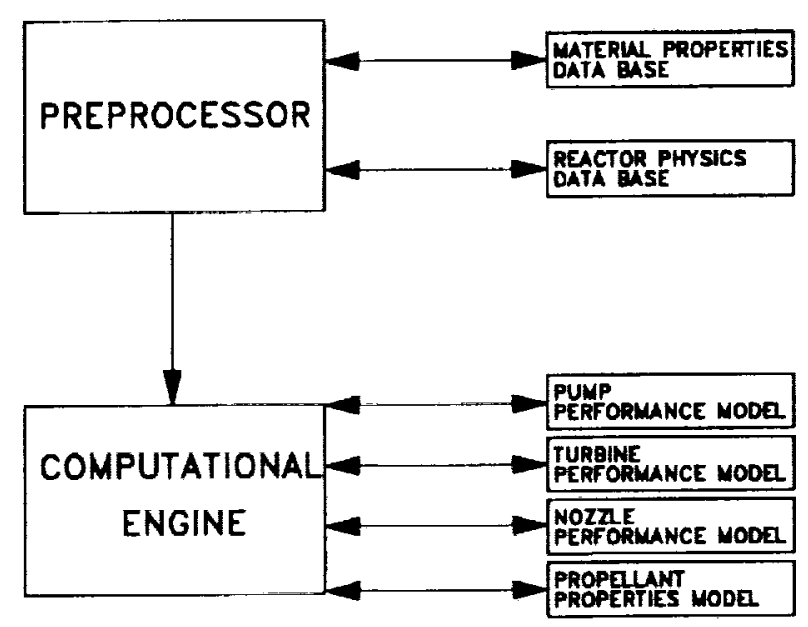

Figure 1. - Level 1 Model Structure.

models accessed by the preprocessor and computational engine is presented in Walton, et al., 1992.

The System Analysis Flow Simulator, SAFSIM, program (Dobranich, 1992) was selected as the base computational engine for the Level 1 NTP system model. Beginning in June 1992, an effort been underway to validate SAFSIM as a steady-state model for NTP systems (Lee, 1993). This work has focused on comparing SAFSIM analyses to experimental data from the NRXA4/EST tests. A majority of the activity was centered around the creation of an input file containing NRX-A4/EST system dimensions, materials, flow areas, loss coefficients and power profiles. The results of SAFSIM analyses are compared to data for two steady-state points from NRX-A4/EST tests in March 1966. The analyses show good agreement. Another figure of merit is the comparison of predicted to measured fuel element coolant channel wall temperature (Figure 2). The predicted values from SAFSIM are below the experimental values from thermocouples slightly imbedded in the channel wall. Comparison of SAFSIM to additional NRX-A4/EST data is a continuing effort; this effort will also be extended to a comparison with $\mathrm{XE}-1$ test data. 
In addition to the validation of the computational engine, work has been initiated on the

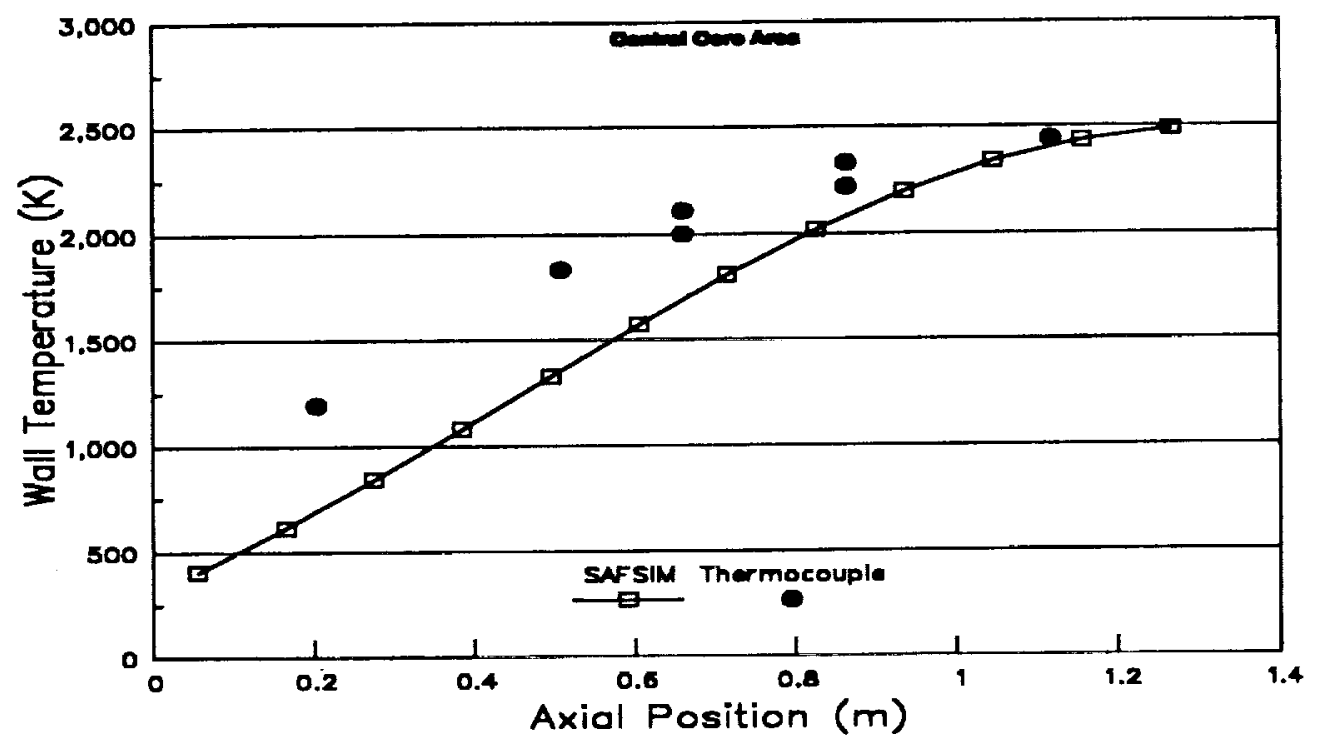

Figure 2. - Predicted versus Measured Wall Temperature.

preprocessor and many of the component models. The first model completed was the propellant properties model (Walton, 1992) which is based on the most recent data from the National Bureau of Standards.

\section{FUTURE DIRECTION}

The accurate prediction of transient performance is critical to system design and testing, as well as to mission design and analysis. The system must start up and shut down in a controllable manner without extreme pressure and temperature gradients or oscillations. Moreover, once shutdown, low propellant flow rates will be used to remove fission-productdecay heat affecting the mission specific impulse. After Level 1, all subsequent models will have transient analysis capability. The Level 2 model will use existing models whereas the 
Level 3 model is anticipated to leverage current and future code development efforts.

The interagency team has begun preliminary planning for the Level 3 model. Because this generic model is envisioned as a state-of-the-art, multidimensional, transient system analysis model, the long lead time necessitates 
Table 1. - Comparison of SAFSIM to NRX-A4/EST Data (CRT 9297.5).

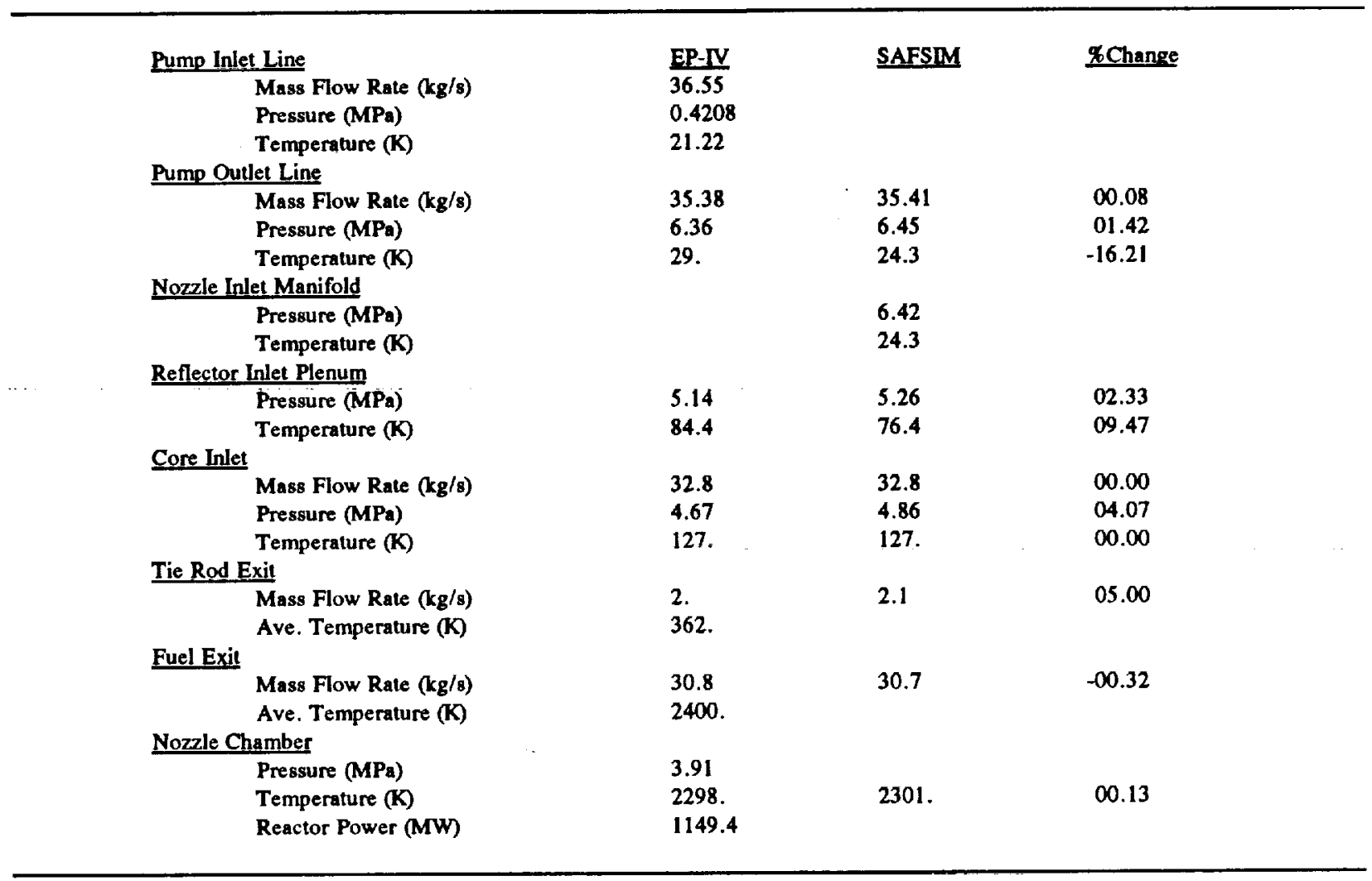

Table 2. - Comparison of SAFSIM to NRX-A4/EST Data (CRT 11190).

Pump Inlet Line

Mass Flow Rate $(\mathrm{kg} / \mathrm{s})$

Pressure (MPa)

Temperature (K)

Pump Outlet Line

Mass Flow Rate $(\mathrm{kg} / \mathrm{s})$

Pressure (MPa)

Temperature (K)

Nozzle Inlet Manifold

Pressure (MPa)

Temperature (K)

Reflector Inlet Plenum

Pressure (MPa)

Temperature (K)

Core Inlet

Mass Flow Rate $(\mathrm{kg} / \mathrm{s})$

Pressure (MPa)

Temperature (K)

Tie Rod Exil

Mass Flow Rate $(\mathrm{kg} / \mathrm{s})$

Ave. Temperature (K)

Fuel Exil

Mass Flow Rate $(\mathbf{k g} / \mathbf{s})$

Ave. Temperature (K)

Nozzle Chamber

Pressure (MPa)

Temperature (K)

Reactor Power (MW)

\begin{tabular}{|c|c|c|}
\hline $\begin{array}{l}\text { EP-IV } \\
35.42 \\
0.4208 \\
21.22\end{array}$ & SAFSIM & SChange \\
\hline $\begin{array}{l}34.28 \pm 0.85 \\
6.421 \\
27.91\end{array}$ & $\begin{array}{l}34.26 \\
6.411 \\
24.21\end{array}$ & $\begin{array}{l}-00.06 \\
-00.16 \\
-13.25\end{array}$ \\
\hline $\begin{array}{l}6.112 \\
28.44\end{array}$ & $\begin{array}{l}6.127 \\
24.21\end{array}$ & $\begin{array}{r}00.25 \\
-14.87\end{array}$ \\
\hline $\begin{array}{l}4.956 \\
74.55\end{array}$ & $\begin{array}{l}5.000 \\
77.90\end{array}$ & $\begin{array}{l}00.88 \\
04.49\end{array}$ \\
\hline $\begin{array}{l}31.92 \\
4.510 \\
126\end{array}$ & $\begin{array}{l}31.90 \\
4.595 \\
130.2\end{array}$ & $\begin{array}{r}-00.06 \\
01.88 \\
03.17\end{array}$ \\
\hline $\begin{array}{l}1.9 \\
355.5\end{array}$ & 2.01 & 05.78 \\
\hline $\begin{array}{l}30 . \\
2330 .\end{array}$ & 29.89 & 00.37 \\
\hline $\begin{array}{l}3.771 \pm 0.034 \\
2225 . \pm 31 \\
1077.7 \pm 35.9\end{array}$ & 2236 & 00.49 \\
\hline
\end{tabular}


early planning. It is expected that this model will be applied to reasonably fixed-system configurations and will leverage new computational technology (Fortran/90, Object Oriented Programming, Parallel Processing) to achieve run times on the order of a few hours for a startup or shutdown analysis case. Several configuration options have been identified for the Level 3 model: the first is to link an existing Monte Carlo reactor code with a transient fluid mechanics (F-M) code, such that the steady-state reactor code is called stepwise with time by the fluid mechanics code; a second is to develop a transient three-dimensional reactor dynamics code and interfacing it with a transient fluid mechanics code; the third, and most difficult, option is to develop a coupled reactor physics and fluid mechanics code. The team concluded that, prior to proceeding with a particular option, experience with the Level 2 model and existing onedimensional transient models should be gained and that experimental validation of existing neutronics models should be completed for these fuel forms.

\section{CONCLUDING REMARKS}

An interagency NASA/DOE effort was initiated to develop several models for predicting the performance of nuclear thermal propulsion systems. These models are being developed to support the evaluation of conceptual designs and to provide a diagnostic tool for understanding system tests. Once verified and validated, these system models will aid in regaining the flightready status of nuclear thermal propulsion vehicles faster, cheaper, better and more safely by verifying design configurations and minimizing full-scale ground tests. 


\section{Acknowledgement}

The author would like to acknowledge the contributions of all participants of the interagency nuclear thermal propulsion system modeling team who have gone beyond the call of duty to provide technical insight and to cultivate management support for this activity: Mr. Nelson Hannan (ANL), Mr. Ken Perkins (BNL), Mr. Tony Zuppero (INEL), Mr. John Buksa (LANL), Mr. Brian Worley (ORNL), Mr. Dean Dobranich (SNL), Mr. Harold Gerrish (MSFC), and Mr. Ken Hampsten (PL). This work was completed with in-house funding from each agency.

\section{References}

Dobranich, Dean: SAFSIM: A Computer Program For Engineering Simulation of Space Reactor System Performance. Presented to the ANS Meeting for Nuclear Technology for Space Exploration, Aug. 1992.

Dobranich, Dean: SAFSIM Input Manual - A Computer Program for the Engineering Simulation of Flow Systems. SAND92-0694, July 1992.

Lee, Stacey K.: Application of a General Fluid Mechanics Program to NTP System Modeling. Presented at the 10th Space Nuclear Power Symposium, Jan. 1993.

Walton, J.T.; Hannan, N.A.; Perkins, K.R.; Buksa, J.J.; Worley, B.A.; Dobranich, D.: System Model Development for Nuclear Thermal Propulsion. IAF-92-0568, Sept. 1992.

Walton, J.T.: NBS Parahydrogen Properties Data Base Program $\left(\mathrm{NBS}^{+} \mathrm{pH}_{2}\right)$. Available through COSMIC as LEW-15505, 1992. 
Public reporting burden for this collection of information is estimated to average 1 hour per response, including the time for revlewing instructions, searching existing data sources, gathering and maintalning the data needed, and completing and reviewing the collection of intormation. Send comments regarding this burden estimate or any other aspect of this collection of information, including surestions for reducing this burden to Washington Headquarters Services, Directorate for intormation Operations an Davis Highway, Suite 1204, Aflington, VA 22202-4302, and to the Office of Management and Budget, Paperwork Reduction Project (0704-0188), Washington, DC 20503.

\begin{tabular}{|l|l|l|}
\hline 1. AGENCY USE ONLY (Leave blank) & $\begin{array}{c}\text { 2. REPORT DATE } \\
\text { December } 1992\end{array}$ & $\begin{array}{r}\text { 3. REPOAT TYPE AND DATES COVERED } \\
\text { Technical Memorandum }\end{array}$ \\
\hline
\end{tabular}

4. TITLE AND SUBTITLE

Development of NASADDOE NTP System Performance Models

6. AUTHOR(S)

James T. Walton

7. PERFORMING ORgANIZATION NAME(S) AND ADDRESS(ES)

National Aeronautics and Space Administration

Lewis Research Center

Cleveland, Ohio 44135-3191

9. SPONSORINGMONITORING AGENCY NAMES(S) AND ADDRESS(ES)

National Aeronautics and Space Administration

Washington, D.C. 20546-0001
5. FUNDING NUMBERS

WU-593-00-71

8. Performing organization REPORT NUMBER

E-7506

10. SPONSORING/MONITORING AGENCY REPORT NUMBER

NASA TM-105982

\section{SUPPLEMENTARY NOTES}

Prepared for the 10th Space Nuclear Power Symposium sponsored by the University of New Mexico Institute for Space Nuclear Power, Albuquerque, New Mexico, January 10-14, 1993. Responsible person, James T. Walton, (216) 433-7047.

12a. DISTRIBUTION/AVAILABILITY STATEMENT

12b. DISTRIBUTION CODE

Unclassified - Unlimited

Subject Category 6 and 20

13. ABSTRACT (Maximum 200 words)

A critical enabling technology in the evolutionary devclopment of Nuclear Thermal Propulsion (NTP) is the ability to predict the system performance under a variety of operating conditions. The ability to predict the system performance is critical for mission analysis and for control subsystem testing, as well as for the modeling of various failure modes. Performance must be accurately predicted during steady-state and transient operation, such as start-up, shut-down and after-cooling. The development and application of verified and validated system models has the potential to reduce testing, cost and time required for the technology to again reach flight-ready status. An integrated NASA/DOE team was formed in late 1991 to develop and implement a strategy for modeling NTP systems. It is the intent of the interagency team to develop several levels of computer programs, which vary in detail, to simulate NTP systems based on either prismatic, particle or advanced fuel forms. This paper presents an overview of the models under development by the interagency team. In addition, the status of the development and validation efforts for the Level 1 steady-state parametric model will be discussed.

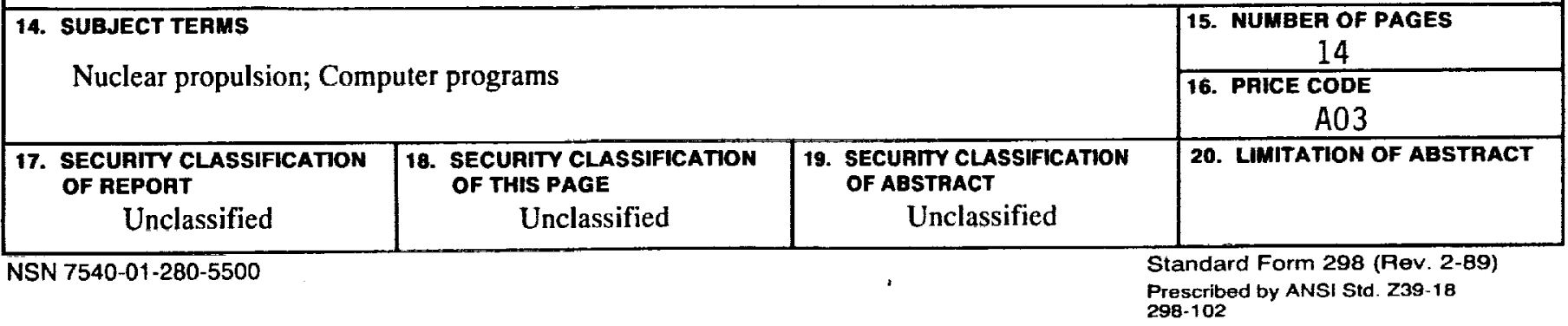

